\section{Angelica sinensis has inherent endothelial cell toxicity at high concentrations but can also protect the vascular endothelium from oxidative stress-induced injury at moderate concentrations}

\author{
Miko Yamada, ${ }^{1}$ Betty K. Pat,1,2 \\ Ken Wojcikowski, ${ }^{3}$ Glenda C. Gobe ${ }^{1}$ \\ 1 Centre for Kidney Disease Research, \\ School of Medicine, The University \\ of Queensland, Brisbane, Australia; \\ 2Department of Medicine, University \\ of Alabama, Birmingham, Alabama, USA; \\ ${ }^{3}$ School of Health and Human Sciences, \\ Southern Cross University, Lismore, \\ Australia
}

\section{Abstract}

Hypoxia and oxidative stress are important factors in the pathogenesis of many acute forms of injury, especially acute kidney injury. Apoptosis is a key mode of endothelial cell death from oxidative stress. Minimising the detrimental effects of oxidative stress is necessary to reduce injury, and new treatment strategies are constantly being sought. The aim of this study was to investigate the ability of an aqueous/methanol extract of Angelica sinensis (AS) root (Chinese names Danggui, Dong quai, Donggui) to protect endothelium from hypoxia and oxidative stress. This was compared in specialised kidney endothelium (renal medullary vascular endothelial cells; RMVEC) versus central endothelium (aortic endothelial cells; AEC). Toxicity of various strengths of AS was first tested in RMVEC and AEC using \% apoptosis and mitosis as outcomes. Morphological and molecular characteristics of apoptosis and mitosis, and the effect of AS on heme-oxygenase-1, a marker of cellular response to oxidative stress, were also investigated. The results showed that, at concentrations of $2500 \mu \mathrm{g} / \mathrm{mL}$ or greater, AS significantly increased apoptosis in RMVEC and AEC $(\mathrm{P}<0.05)$, however concentrations of 2000 $\mu \mathrm{g} / \mathrm{mL}$ or less were non-toxic and also nonmitogenic. Endothelial cells were then treated with hydrogen peroxide ( $0.8 \mathrm{mM}$ for RMVEC; $0.6 \mathrm{mM}$ for AEC) for oxidative stress, with and without $2000 \mu \mathrm{g} / \mathrm{mL}$ AS. AS significantly inhibited oxidant-induced apoptosis $(\mathrm{P}<0.05)$ but had little effect on mitosis. AS also increased heme-oxygenase-1, but only in AEC. AS extracts may have some inherent toxicity at high concentrations, but with careful analysis of non-toxic levels, both renal and central endothelium benefited from AS against oxidative stress-induced apoptosis, without inducing excessive mitosis, and AS may find application in some oxidant-induced disease.

\section{Introduction}

Hypoxia and oxidative stress are important factors in the pathogenesis of many acute forms of injury, especially those involving endothelial cell damage. Acute renal failure and injury, now termed acute kidney injury (AKI), 1 are particularly important, as the outcome is death in approximately $30-50 \%$ of cases, especially those in the intensive care units. ${ }^{2}$ Many injurious factors contribute to AKI, but one of the key factors is oxidative stress. $^{3-6}$ In the kidney, an important and common cause of AKI is ischaemia-reperfusion injury. ${ }^{7}$ Not only is the tubular epithelium affected, but also the vascular endothelium, 8,9 the latter cell type being particularly prone to oxidative stress damage. There is some evidence that extracts of the root of Angelica sinensis (AS) have beneficial effects on human vascular endothelial cells affected by oxidized low density lipoprotein. ${ }^{10}$ In the kidney, AS has also been used with Astragalus membranaceous for beneficial effect on renal tubular epithelium after ischemia-reperfusion, ${ }^{11}$ with anti-apoptotic, mitogenic and angiogenic activities noted. Wojcikowski and colleagues used these combined herbal extracts with the anti-fibrotic angiotensin-converting enzyme inhibitor drug enalapril and reported an additive anti-fibrotic benefit after unilateral ureteral obstruction. ${ }^{12}$ However, the effects of AS on the vascular endothelium are not known, especially in the acutely-injured kidney.

With reference to structural changes of AKI, the relative contributions of necrosis or apoptosis vary, depending on the severity of the damage.4,13 Necrosis causes extensive loss of renal tubular epithelium, as well as vascular endothelium, and also initiates an inflammatory response in vivo. ${ }^{14}$ Apoptosis is thought to be less damaging, with single cell loss that is driven by a molecular apoptotic program and little initiation of acute inflammation. 15 In both cases, if the damage is not too extensive then the remaining epithelial and endothelial cells can repair by initiating a regenerative change. Thus, recovery from AKI depends not only on the initiation of replacement or regeneration of cells deleted by cell death, but also on minimising cell death. A similar scenario exists for most ischemia-reperfusion injured tissues and organs.

This investigation tested the hypothesis that AS would protect vascular endothelial cells, particularly those originating from the kidney, from cell death induced by oxidative
Correspondence: Glenda Gobe, Centre for Kidney Disease Research, School of Medicine, Univ of Queensland, Building 33 Princess Alexandra Hospital, Woolloongabba, Brisbane, Australia, 4102. Tel. +61.7.31765655 - Fax: +61.7.31762970.

E-mail: g.gobe@uq.edu.au

Key words: Apoptosis, acute kidney injury, oxidative stress, endothelium, Angelica, antioxidant.

Acknowledgements: Pharmacognosist Dr Hans Wohlmuth, Medicinal Plant Herbarium, Southern Cross University, Lismore, Australia is acknowledged for authenticating the sample of Angelica sinensis root and depositing voucher samples at the Medicinal Plant Herbarium. Miko Yamada has received support for her research from the ANZ Foundation Australia, the Royal Children's Hospital Foundation, Brisbane Australia, and the Perinatal Research Centre and the Centre for Kidney Disease Research, The University of Queensland, Australia

Conflict of interest: the authors report no conflicts of interest.

Received for publication: 2 February 2011. Accepted for publication: 14 July 2011.

This work is licensed under a Creative Commons Attribution NonCommercial 3.0 License (CC BYNC 3.0).

(C) Copyright M. Yamada et al., 2011

Licensee PAGEPress, Italy

Alternative Medicine Studies 2011; 1:e8

doi:10.4081/ams.2011.e8

stress, and also restore proliferative or regenerative capacity. Because of the reported heterogeneity of vascular endothelial cells, 16 two different endothelial cells lines were used so that a comparison could be made between renal and major vessel endothelial cells. Understanding the mechanisms involved in promotion of regeneration and controlling cell death processes is crucial to improving patient outcome from oxidant-induced injury.

\section{Materials and Methods}

\section{Cell lines and culture methods}

The two characterised cell lines were: rat renal medullary vascular endothelial cells (RMVEC; a gift from M. Goligorsky, New York Medical College, Valhalla NY, USA);17 and bovine aortic endothelial cells (AEC, American Type Culture Collection, Rockville, MA, USA). Both grow as adherent cultures and, for treatments, were grown to $80-90 \%$ confluence on glass coverslips (13 mm diameter; Lomb Scientific, Taren Point, NSW, Australia) in tissue culture multi-well plates, or in tissue cul- 
ture flasks and Petri dishes in defined growth medium. RMVEC and AEC were grown in Dulbecco's modified Eagle's medium (DMEM) supplemented with $10 \%$ newborn calf serum (Trace Scientific, Noble Park, Australia), penicillin $(1000 \mathrm{U} / \mathrm{mL})$ and streptomycin (1000 $\mu \mathrm{g} / \mathrm{mL}$ ) (BioWhittaker, Edward Keller Pty Ltd, Halam, Australia), in a humidified atmosphere of $5 \%$ carbon dioxide $\left(\mathrm{CO}_{2}\right)$ in air at $37^{\circ} \mathrm{C}$ in a tissue culture incubator.

\section{Preparation of extracts from Angelica sinensis}

AS root (Chinese names Danggui, Dong quai, Donggui; Voucher number NCM-D07040) was part of a much larger specimen that had been authenticated by pharmacognosist Mr Hans Wohlmuth, Medicinal Plant Herbarium, Southern Cross University, Lismore, Australia. The sample was authenticated by chemical and morphological comparison with authenticated reference material. Voucher samples were deposited in the Medicinal Plant herbarium and part provided for use in this project. The sample was of both upper and lower roots, and was grown in the Hubei Province in China, in partial shade, and harvested in mid-autumn after the first year of growth. The part sample provided for our use was dried, powdered and then extracted sequentially with ethyl acetate $(10 \mathrm{~mL}, 3$ times), methanol (10 $\mathrm{mL}, 3$ times), and $0 \%$ aqueous methanol (10 mL, 3 times), following the methods of Wojcikowski et al. ${ }^{18}$ Figure 1 demonstrates the sequential extraction of AS to an aqueous: methanol extract (1:1, volume to volume). The sequential extracts were concentrated using a rotary evaporator, and the dried extracts were then weighed and dissolved in dimethyl sulfoxide (DMSO) to make a final stock concentrations of $100 \mathrm{mg} / \mathrm{mL}$. These were then stored at $4^{\circ} \mathrm{C}$. The aqueous:methanol extract had greatest antioxidant capacity,18 and this extract was used for experiments reported here.

\section{Cell treatments}

Does the aqueous methanol extract of AS have inherent toxicity? To select a non-toxic treatment concentration of the aqueous: methanol extract of AS, this was tested at concentrations from 50 to $3000 \mu \mathrm{g} / \mathrm{mL}$. Control medium contained DMSO at the volume for the $3000 \mu \mathrm{g} / \mathrm{mL}$ concentration of AS, that is, at $30 \mu \mathrm{L} / \mathrm{mL}$ medium. Cells were treated for $18-20$ $\mathrm{h}$ and then assessed for indication of toxicity (increased apoptosis, decreased mitosis at significant levels). The results are detailed later, but the highest concentration of AS that caused no increase in toxicity for both cell lines was $2000 \mu \mathrm{g} / \mathrm{mL}$. To optimize potential protective/anti-oxidant effect of AS, this treatment concentration was used for further experiments. Does AS protect against oxidative stress in vascular endothelium? To model the effects of oxidative stress on the vascular endothelium, low levels of hydrogen peroxide $\left(\mathrm{H}_{2} \mathrm{O}_{2}\right)$ were used as published previously by us. 19,20 These studies had demonstrated that $\mathrm{H}_{2} \mathrm{O}_{2}$ concentrations that caused a significant increase in apoptosis without loss of adhesion of non-apoptotic cells, and no necrosis, were $0.8 \mathrm{mM}$ for RMVEC and $0.6 \mathrm{mM}$ for AEC. Thus, these concentrations were used to cause injury to renal endothelium that might be considered similar to in vivo oxidative stress damage. ${ }^{20}$ Cells were treated with $\mathrm{H}_{2} \mathrm{O}_{2}$ with or without $2000 \mu \mathrm{g} / \mathrm{mL}$ AS. Controls had equivalent amounts of DMSO vehicle as the AS therapy $(20 \mu \mathrm{L} / \mathrm{mL})$. Cells were analysed at $18-20 \mathrm{~h}$ for apoptosis (morphology, ApopTag) and mitosis (morphology, proliferating cell nuclear antigen/PCNA).

\section{Cell structure: apoptosis and mitosis}

Fixation and staining of cells: at the end of treatment times, cultures were checked for any cells that had lost adherence from the growth coverslips or dishes, then the supernatant was removed, cells on coverslips were washed with phosphate buffered saline (PBS) pH 7.4, and fixed in $4 \%$ buffered paraformaldehyde for 30 min at $4^{\circ} \mathrm{C}$, washed twice with PBS, then stained routinely for microscopy with haematoxylin and eosin (H\&E). ${ }^{15}$ Cells on coverslips were dehydrated in $100 \%$ ethanol, cleared in xylene, and then mounted onto glass slides using Depex mounting medium for light microscopy and photography.

Apoptosis: Apoptosis was first recognized microscopically in H\&E-stained cells at x200 magnification by its morphological characteristics. Methods are published previously. ${ }^{15}$ In brief, characteristics included shrunken eosinophilic cells with condensed, marginated nuclear chromatin and intact cell membrane, and discrete apoptotic bodies comprising large, dense, pyknotic nuclear fragments usually surrounded by a narrow eosinophilic cytoplasmic rim. Cells or apoptotic bodies with nuclear features of apoptosis but showing the characteristics of secondary degeneration, similar to necrosis and known to occur in cell culture, 15 were also counted as apoptosis. Primary necrosis was sought but not observed. Apoptotic cells were counted in at least 5 microscopic fields with a minimum of 1000 cells counted in total. Counts of apoptosis were calculated as a percentage of total cells (normal plus apoptotic) per x200 microscope field. To verify the presence of apoptosis using biochemical means, the ApopTag ${ }^{\circledR}$ peroxidase in situ apoptosis detection kit (Serological Corporation, Millipore Pty Ltd, North Ryde, Australia), was used according to the supplier's protocol, with appropriate positive and negative controls. This kit labels apoptotic cells

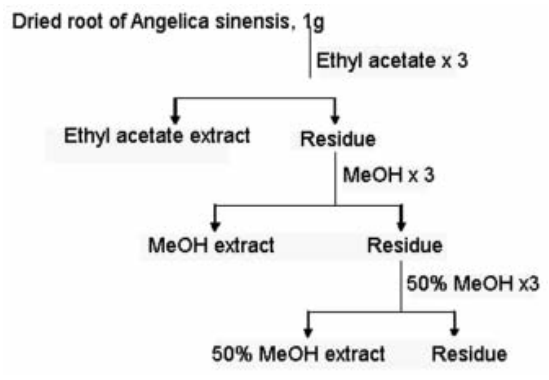

Figure 1. Extraction process for Angelica sinensis root. The extraction process leading to the $50 \%$ aqueous:methanol extract, used as treatment in this model, is demonstrated.

by modifying DNA fragments utilizing terminal deoxynucleotidyl transferase for detection of apoptotic cells by specific staining.

Mitosis: Mitotic cells were assessed microscopically at x200 in H\&E-stained cells on the basis of spindle formation or cytokinesis. Formation of mitotic spindles occurs during metaphase and remains visible in anaphase. Cells in the latter stage of mitosis (telophase or undergoing cytokinesis) were also easily seen. Mitotic cells were counted in at least 5 microscopic fields at x200 magnification and at least 1000 cells were counted. Counts of mitosis were calculated as a percentage of totals cells (normal plus mitotic) per microscope field. The morphological assessment of mitosis was verified using proliferating cell nuclear antigen (PCNA) and immunohistochemistry (IHC). IHC methods have been published by us previously. ${ }^{21}$ In brief, PCNA primary antibody (DAKO, Botany, NSW, Australia; 1:100 dilution) was used in a peroxidase-antiperoxidase method. Non-specific binding of peroxidase or antibody was blocked with $0.3 \%$ $\mathrm{H}_{2} \mathrm{O}_{2}$ in $4 \%$ skim milk powder followed by incubation in diluted normal rabbit or goat serum. The peroxidase-anti-peroxidase reaction plus the chromogen diaminobenzidine tetrahydrochloride (DAB) were used for visualization. Negative controls were prepared without primary antibody, or with non-specific serum.

\section{Protein extraction and analysis of heme oxygenase-1}

H0-1 is a marker of oxidative stress and anti-oxidant capacity.22 Cultures (control or treated) for protein extraction were grown in $100 \mathrm{~mm}^{2}$ Petri dishes. Each dish routinely contained a coverslip that was fixed and stained with H\&E to compare morphological changes with any changes in protein expression measured by Western immunoblot methods. ${ }^{21}$ Cells were washed in ice-cold PBS then disrupted on ice with RIPA cell lysis buffer containing protease and phosphatase inhibitors $(10 \mu \mathrm{g} / \mathrm{mL}$ leupeptin, $10 \mu \mathrm{g} / \mathrm{mL}$ aprotinin, $100 \mu \mathrm{g} / \mathrm{mL}$ phenylmethanesulphonyl fluoride, $1 \mathrm{mM}$ sodi- 
um orthovanadate) (Sigma-Aldrich, Botany, Australia). Cell debris was removed by centrifugation at $16,000 \mathrm{~g}$ for $15 \mathrm{~min}$ at $4^{\circ} \mathrm{C}$ and protein concentration was determined using a Bradford protein assay and spectroscopy. $40 \mu \mathrm{g}$ of total cell lysate were loaded onto each lane. Protein was resolved using a $10 \%$ sodium dodecylsulphate (SDS) polyacrylamide gel at $100 \mathrm{~V}$ with a current of $60 \mathrm{mAmps}$, then transferred to a Polyscreen ${ }^{\circledR}$ polyvinylidene difluoride membrane (Perkin Elmer, Melbourne, Australia) using a Bio-Rad Mini Protean 3 unit (Bio-Rad Australia). To prevent non-specific binding of antibodies, membranes were blocked in 5\% non-fat skim milk in Tris buffered saline-Tween (TBST) buffer (5\% blotto) for $1 \mathrm{~h}$ at room temperature with gentle agitation. Membranes were then incubated in primary antibody (HO-1; StressGen, BC, Canada; $1: 1000$ ) diluted in 5\% blotto and incubated overnight at $4^{\circ} \mathrm{C}$ on a rocking platform. Blots were washed in TBST then incubated with horse-radish peroxidase (HRP)-conjugated secondary antibody diluted 1:2000 in 5\% blotto for $1 \mathrm{~h}$ at room temperature. Membranes were washed in TBST containing $0.1 \%$ Igepal CA-630, and then incubated with Supersignal West Pico chemiluminescent substrate (Pierce Biotechnology, Rockford, IL, USA). Protein bands were detected using enhanced chemiluminescence imaging onto X-ray film (Fuji Rx XR) and scanned using a Hewlett Packard Scan Jet $3200 \mathrm{C}$ at 300 dpi. Scion Image software (vß4.0.2) was used to quantify the density of protein bands minus local background in arbitrary densitometry units. The membranes were stained with Coomassie blue (SigmaAldrich) to verify equal protein loading of lanes and protein bands were normalized against pan-actin using Western blot methods.

\section{Statistical analysis}

The \% apoptosis, mitosis and arbitrary densitometry units were expressed as mean \pm standard error of the mean (SE). All results were analysed by One-Way Analysis of Variance (ANOVA) and Dunnet's multiple comparison post-hoc test, where relevant, for comparison of 2 or more groups. Significance was considered to be $\mathrm{P}<0.05$.

\section{Results}

Outcome of toxicity and mitosis trial for AS Serial concentrations of AS (50 to 3000 $\mu \mathrm{g} / \mathrm{mL}$; stock solution $100 \mu \mathrm{g} / \mu \mathrm{L}$ ) were added to RMVEC and AEC cultures to determine a maximal treatment concentration that did not cause a significant increase in apoptosis, and/or decrease in mitosis. These results are presented in Figure 2. In general, AS induced higher levels of apoptosis at lower levels of AS

in AEC than RMVEC. In RMVEC, at $2500 \mu \mathrm{g} / \mathrm{mL}$ AS, there was a significant increase in toxicity of AS (24.0 $\pm 0.5 \%$ apoptosis) compared with DMSO controls $(3.9 \pm 1.6 \%)(\mathrm{P}<0.05)$. There were no significant differences amongst scores for mitosis in RMVEC with any of the AS concentrations. In AEC, there was a gradual but non-significant rise in apoptosis up to $2000 \mu \mathrm{g} / \mathrm{mL} \mathrm{AS}$, with this increase reaching significance at $2500 \mu \mathrm{g} / \mathrm{mL}$ AS $(11.2 \pm 2.1 \%$ versus $2.1 \pm 1.5 \%$ in DMSO controls, $\mathrm{P}<0.05)$. In addition, there was no significant change in mitosis to the $2000 \mu \mathrm{g} / \mathrm{mL}$ concentration, after which there was a negation of mitosis. At 3000 $\mu \mathrm{g} / \mathrm{mL} \mathrm{AS}$, there was also loss of cell adhesion in approximately $50 \%$ of cells. Thus, 2000 $\mu \mathrm{g} / \mathrm{mL}$ was selected as a non-toxic AS therapy concentration with potentially the greatest anti-oxidant ability. 18

\section{Modulation of oxidative stress- induced endothelial injury by AS}

Figures 3 (bar graphs) and 4 (histology, ApopTag, PCNA) demonstrate these results. H202 caused a significant increase in apoptosis in both cell lines compared with control cultures
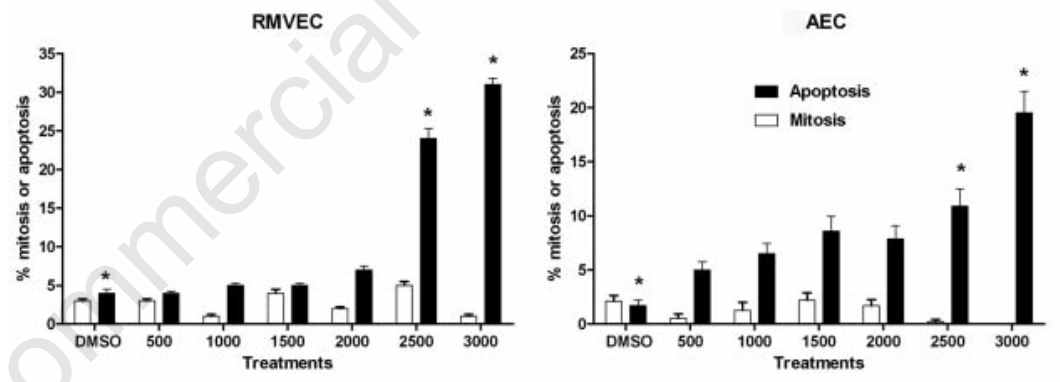

Figure 2. Toxicity and mitogenesis test of Angelica sinensis. Serial concentrations of AS ( 50 to $3000 \mu \mathrm{g} / \mathrm{mL}$ ) were added to renal medullary vascular endothelial cells and aortic endothelial cells to determine a maximal treatment concentration that did not cause significant increases in apoptosis, and/or decreases in mitosis. Bar graphs represent mean \pm $\mathrm{SE}$ of counts of mitosis and apoptosis following 18-20 h treatment with AS. *Indicates $\mathbf{P}<0.05$ compared to DMSO control levels.

RMVEC

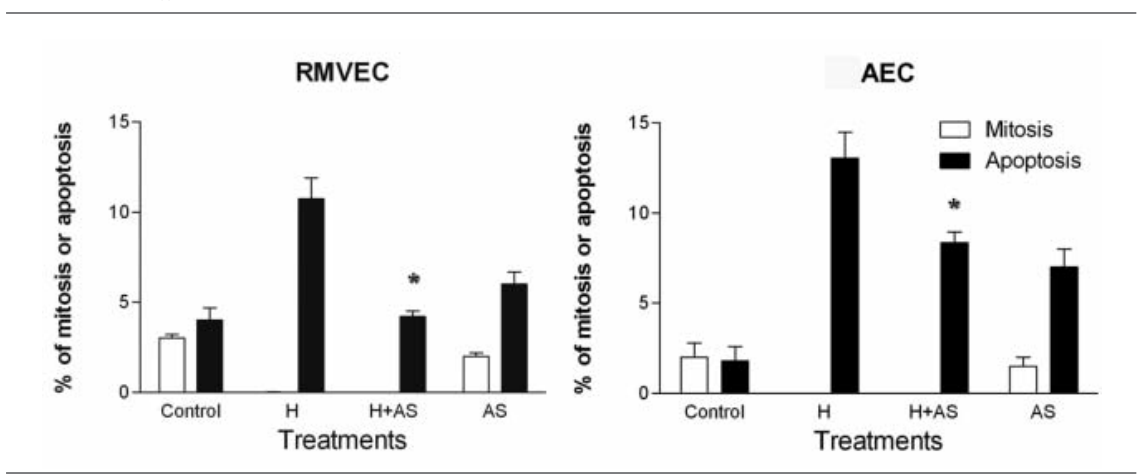

with DMSO $(\mathrm{P}<0.05)$. In both cell lines, AS caused a significant decline in $\mathrm{H}_{2} \mathrm{O}_{2}$-induced apoptosis $(\mathrm{P}<0.05)$. Although AS returned mitosis, that had been negated by oxidative stress, to base control levels, it should be noted that there was also no excessive mitogenesis/angiogenesis from the AS treatment, something that would have been a concern for induction of vascular cancers in the AS-treated cultures without oxidative stress.

\section{Modulation of HO-1 protein expression by AS}

Figure 5 shows a representative $\mathrm{HO}-1$ Western blot of cell lysates from RMVEC and AEC treated with $\mathrm{H}_{2} \mathrm{O}_{2}$ with or without AS. RMVECs had strong endogenous HO-1 levels that were reduced under $\mathrm{H}_{2} \mathrm{O}_{2}$ conditions but were not further altered by AS treatment. The AS control cultures had expression levels similar to DMSO vehicle control cultures. In AEC, there were low endogenous levels of $\mathrm{HO}-1$ which were not altered by $\mathrm{H}_{2} \mathrm{O}_{2}$ but $\mathrm{AS}$ produced a marked increase in $\mathrm{HO}-1$ expression with or without $\mathrm{H}_{2} \mathrm{O}_{2}$, indicating improvement in anti-oxidant capacity with AS.

Figure 3. Effects of Angelica sinensis on oxidative stress-induced injury. Bar graphs represent means $\pm S E$ of counts for apoptosis and mitosis for oxidative stress with and without AS in renal medullary vascular endothelial cells (RMVEC) and aortic endothelial cells (AEC). ${ }^{*}$ Indicates $\mathrm{P}<0.05$ compared to $\mathrm{H}_{2} \mathrm{O}_{2}$ treated cultures. $\mathrm{H}_{2} \mathrm{O}_{2}$ caused a significant increase in apoptosis in both cell lines. AS caused a significant decline in apoptosis induced by oxidative stress. Although AS returned mitosis to base control levels, it did not increase mitosis above control levels in either cell line with oxidative stress. 


\section{Discussion}

The root of AS is an important Chinese medicine, tradionally used for treatment of blood disorders such as anaemia, and other human health problems such as amenorrhea, hypertension and other cardiovascular disorders, asthma, bronchitis, and rheumatism. ${ }^{23}$ Extracts of the root of AS have been reported to have beneficial effects on human vascular endothelium affected by oxidized low density lipoprotein. 10 The active ingredients of AS root, determined by gas chromatography-mass spectroscopy, are thought to be ferulic acid, ligustilide and other phthalides such as butylidenephthalide, but others may be involved in AS activity. The levels of these constituents are known to be variable, depending on the region and climate where the plants were grown.23 Nonetheless AS root, known best as Danggui, is in great demand throughout the world.

One of the concerns of medicinal herbal usage is that there may be a toxic effect on different cellular components of the body, particularly the kidney. ${ }^{24}$ In these experiments, we have demonstrated that AS therapy may have some inherent toxicity at high concentrations, but at moderate levels it protected both renal and central vascular endothelium against oxidative stress-induced apoptosis, did not induce excessive mitosis, and had differences in outcome between renal and central endothelium in the induction of HO-1. These findings suggest that AS confers cytoprotection against oxidative stress-induced apoptosis and this beneficial effect is, at least in part, mediated through an antioxidant function. Thus, the results are in good agreement with previous findings showing that AS extracts prevented cell death or apoptosis, in many cases induced by oxidative stress, in neuronal, gut, cardiac, and renal epithelial cells. ${ }^{11,25-27}$ The anti-oxidant ability of AS has been published previously, using various oxidative stress tests. 18,28

Although both nephrotoxicity and ischemiareperfusion are common causes of AKI involving oxidative stress, ${ }^{13}$ ischemia-reperfusion is the more common cause of injury. ${ }^{7}$ Mechanisms for development of renal dysfunction and injury in ischaemia-reperfusion-induced AKI involve apoptosis and necrosis, and inflammation. Thus the present study, involving cytoprotection of the renal vascular endothelium by $\mathrm{AS}$, is particularly relevant. No vascular endothelial necrosis was detected, but the significantly increased levels of apoptosis induced by oxidative stress were normalized completely by the concurrent AS treatment. Cytoprotection of the vasculature may provide some anti-inflammatory potential, whereby a reduction in vascular destruction and leakiness during injury reduces the efflux of leucocytes to the point of injury. This is thought to be one of the reasons for exacerbation of

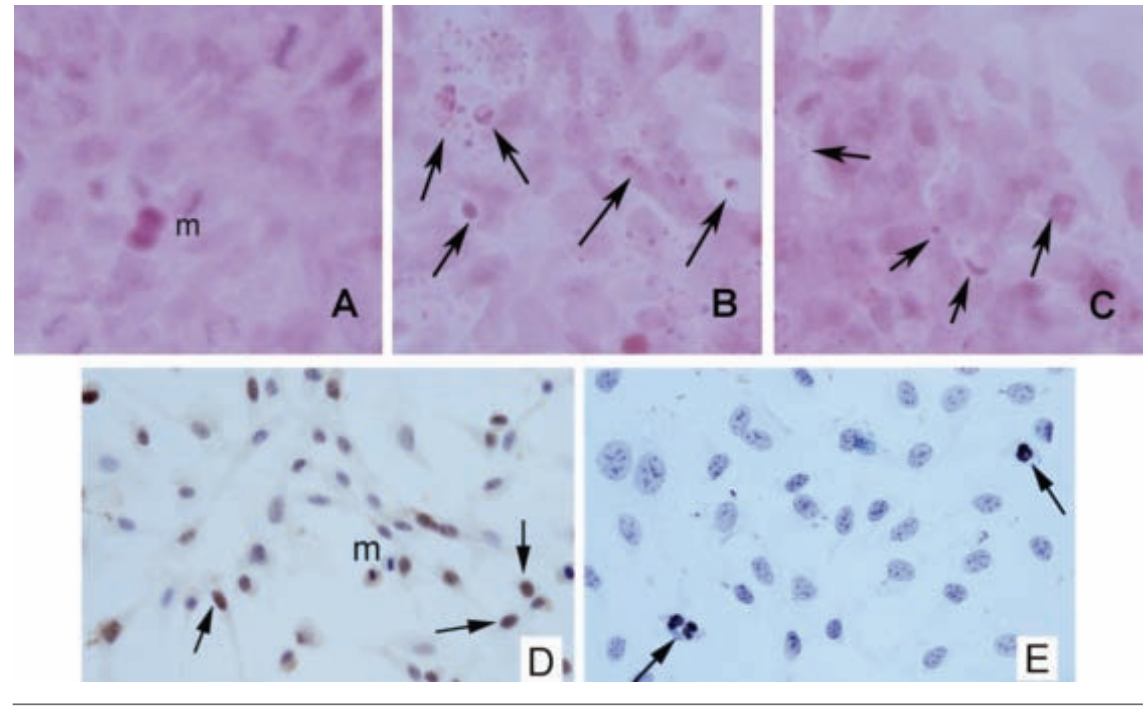

Figure 4. Apoptosis and mitosis in RMVEC and AEC cultures during oxidative stress. In A-C, representative histology in RMVEC cultures is demonstrated for H\&E-stained cells, for control (A), $\mathrm{H}_{2} \mathrm{O}_{2}$-treated (B), and $\mathrm{H}_{2} \mathrm{O}_{2}$-treated with AS. Examples of mitosis are indicated with $\mathrm{m}$ and apoptosis with arrows. In $\mathrm{D}$, examples of PCNA-stained nuclei are demonstrated. In E, examples of ApopTag-stained nuclei are demonstrated.

renal injury during AKI,14 and perhaps one of the reasons why AS therapy might be protective. Ischemia-reperfusion also exacerbates vasospasm and thus is a critical determinant of the extent of ischemic organ injury. ${ }^{29}$ One could speculate that cytoprotection of the renal vascular endothelium by AS has the potential to improve overall health by reducing the local ischemic organ injury.

$\mathrm{HO}-1$ is a $32 \mathrm{kDa}$ protein known to be upregulated in response to stress such as oxidative stress, and protect against cell death. ${ }^{22,30} \mathrm{HO}-1$ is the first and rate limiting enzyme that catalyses heme degradation to biliverdin, liberating carbon monoxide and free iron in the process. It is likely that the anti-oxidant capacity of AS could be indicated not only by amelioration of cell damage induced by oxidative stress, but also stimulation of HO-1 with AS therapy. The mechanisms by which HO-1 counteracts oxidative stress and apoptosis in vascular endothelium following AKI remain unclear. A recent study demonstrated that a truncated form of HO-1 is translocated into the nucleus of cells after hypoxic exposure. This translocation activated oxidant responsive transcription factors and protected cells against $\mathrm{H}_{2} \mathrm{O}_{2}$-mediated injury. ${ }^{25}$ Thus, analysis of nuclear HO-1 should be considered in future studies of mechanisms of antioxidant protection by AS. Modulation of HO-1 has also been shown to have anti-inflammatory therapy potential, ${ }^{30}$ and this mechanism is augmented by AS treatment.

\section{Conclusions}

AS treatment may provide significant protection against oxidative stress-induced cyto-

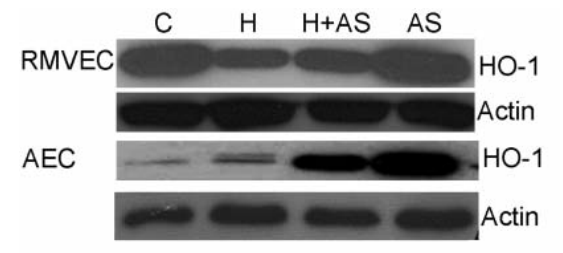

Figure 5. Modulation of HO-1 expression by Angelica sinensis during oxidative stress. Representative Western blots of HO-1 expression $(32 \mathrm{kDa})$ are demonstrated for RMVEC and AEC, for control (C), $\mathrm{H}_{2} \mathrm{O}_{2}(\mathrm{H}), \mathrm{H}_{2} \mathrm{O}_{2}$ with AS $(\mathrm{H}+\mathrm{AS})$, and AS alone (AS) in cell lysates after 18-20 h of treatment. Representative pan-actin blots indicate even loading of lanes for each of RMVEC and AEC.

toxicity in renal and central vascular endothelium, without causing excessive angiogenesis. The present study demonstrated, for the first time, that antioxidant and anti-apoptotic properties of AS may contribute to its protective potential in oxidative damage to renal vascular endothelium.

\section{References}

1. Warnock DG. Towards a definition and classification of acute kidney injury. J Am Soc Nephrol 2005;16:3149-50.

2. Kellum JA, Gibney RT, Tumlin J, et al. Primary prevention of acute renal failure in the critically ill. Curr Opin Crit Care 2005;11:537-41.

3. Percy C, Waters MJ, Gobe G. Caveolins in 
the repair phase of acute renal failure after oxidative stress. Nephrology (Carlton) 2004;9:374-80.

4. Gobe GC, Johnson DW. Distal tubular epithelial cells of the kidney: Potential support for proximal tubular cell survival after renal injury. Int J Biochem Cell Biol 2007;39:1551-61.

5. Haase M, Bellomo R, Haase-Fielitz A. Novel biomarkers, oxidative stress, and the role of labile iron toxicity in cardiopulmonary bypass-associated acute kidney injury. J Am Coll Cardiol 2010;55:2024-33.

6. Heyman SN, Rosen S, Khamaisi M, et al. Reactive oxygen species and the pathogenesis of radiocontrast-induced nephropathy. Invest Radiol 2010;45:188-95.

7. Roman RJ, Akbulut T, Park F, Regner KR. 20-HETE in acute kidney injury. Kidney Int 2011;79:10-13.

8. Le Dorze M, Legrand M, Payen D, Ince C. The role of the microcirculation in acute kidney injury. Curr Opin Crit Care 2009; 15:503-8.

9. Sutton TA. Alteration of microvascular permeability in acute kidney injury. Microvasc Res 2009;77:4-7.

10. Xiaohong Y, Jing-Ping OY, Shuzheng T. Angelica protects the human vascular endothelial cell from the effects of oxidized low-density lipoprotein in vitro. Clin Hemorheol Microcirc 2000;22:317-23.

11. Cai Q, Li X, Wang H. Astragali and Angelica protect the kidney against ischemia and reperfusion injury and accelerate recovery. Chin Med J (Engl) 2001;114:119-23.

12. Wojcikowski K, Wohlmuth H, Johnson DW, Gobe G. Effect of Astragalus membranaceus and Angelica sinensis combined with Enalapril in rats with obstructive uropathy. Phytother Res 2010;24:87584.

13. Gobe GC, Endre ZH. Cell death in toxic nephropathies. Semin Nephrol 2003;
23:416-24.

14. Devarajan P. Update on mechanisms of ischemic acute kidney injury. J Am Soc Nephrol 2006;17:1503-20.

15. Hughes J, Gobe G. Identification and quantification of apoptosis in the kidney using morphology, biochemical and molecular markers. Nephrology (Carlton) 2007; 12452-8.

16. Murphy HS, Bakopoulos N, Dame MK, et al. Heterogeneity of vascular endothelial cells: differences in susceptibility to neutrophil-mediated injury. Microvasc Res 1998;56:203-11.

17. Tsukahara H, Ende H, Magazine HI, et al. Molecular and functional characterization of the non-isopeptide-selective ETB receptor in endothelial cells. Receptor coupling to nitric oxide synthase. J Biol Chem 1994; 269:21778-85.

18. Wojcikowski K, Stevenson L, Leach D, et al. Antioxidant capacity of 55 medicinal herbs traditionally used to treat the urinary system: a comparison using a sequential three-solvent extraction process. J Altern Complement Med 2007; 13:103-9.

19. Hogg N, Browning J, Howard T, et al. Apoptosis in vascular endothelial cells caused by serum deprivation, oxidative stress and transforming growth factorbeta. Endothelium 1999;7:35-49.

20. Pat BK, Cuttle L, Watters D, et al. Fibrogenic stresses activate different mitogen-activated protein kinase pathways in renal epithelial, endothelial or fibroblast cell populations. Nephrology (Carlton) 2003;8:196-204.

21. Percy CJ, Brown L, Power DA, et al. Obesity and hypertension have differing oxidant handling molecular pathways in age-related chronic kidney disease. Mech Ageing Dev 2009;130:129-38.

22. Immenschuh S, Baumgart-Vogt E, Mueller
S. Heme oxygenase-1 and iron in liver inflammation: a complex alliance. Curr Drug Targets 2010;11:1541-50.

23. Lao SC, Yang FQ, Li SP, et al. Identification and quantification of 13 components in Angelica sinensis (Danggui) by gas chromatography-mass spectroscopy couples with pressurized liquid extraction. Analytica Chimica Acta 2005;526:131-7.

24. Wojcikowski K, Johnson DW, Gobe G. Medicinal herbal extracts--renal friend or foe? Part two: herbal extracts with potential renal benefits. Nephrology (Carlton) 2004;9:400-5.

25. Lin Z, Zhu D, Yan Y, et al. An antioxidant phytotherapy to rescue neuronal oxidative stress. Evid Based Complement Alternat Med, 2008.

26. Wong VK, Yu L, Cho CH. Protective effect of polysaccharides from Angelica sinensis on ulcerative colitis in rats. Inflammopharmacology 2008;16:162-7.

27. Yu Y, Du JR, Wang CY, Qian ZM. Protection against hydrogen peroxideinduced injury by Z-ligustilide in PC12 cells. Exp Brain Res 2008;184:307-12.

28. Yang X, Zhao Y, Zhou Y, et al. Component and antioxidant properties of polysaccharide fractions isolated from Angelica sinensis (OLIV.) DIELS. Biol Pharm Bull 2007;30:1884-90.

29. Kharbanda RK, Peters M, Walton B, et al. Ischemic preconditioning prevents endothelial injury and systemic neutrophil activation during ischemia-reperfusion in humans in vivo. Circulation 2001;103: 1624-30.

30. Paine A, Eiz-Vesper B, Blasczyk R, Immenschuh S. Signaling to heme oxygenase-1 and its anti-inflammatory therapeutic potential. Biochem Pharmacol 2010;80:1895-903. 